\title{
1 Experimental Study on Earthquake-induced Falling \\ 2 Debris of Exterior Infill Walls and its Impact to \\ 3 Pedestrian Evacuation
}

4 Xinzheng Lu, ${ }^{\text {a) }}$ Zhebiao Yang, ${ }^{\text {a) }}$ Cheavpor Chea, ${ }^{\text {a) }}$ and Hong Guan ${ }^{\text {) }}$

Under the combined effects of in-plane deformation and out-of-plane acceleration during an earthquake, cracking occurs in the exterior infill walls of buildings causing debris to fall. The falling debris ineluctably blocks roads and hinder fast pedestrian evacuations. To identify the failure criterion for exterior infill walls, specialized test apparatus was designed, and pseudo-static experiments of infill walls were conducted in this work. The influences of different height-to-thickness ratios, drift ratios and out-of-plane accelerations on falling debris were taken into consideration in the proposed apparatus design. The experiment indicated that the infill blocks fell sooner and the falling area was larger for a thinner infill wall with a larger tilting angle. Based on the experimental results, a prediction model was proposed to evaluate the percentage of falling area of infill walls. Using the proposed failure criterion, a pedestrian evacuation simulation was conducted on the Tsinghua University campus as a case study. Moreover, the debris distribution and evacuation results under different earthquake intensities were also analyzed. The results of the case study revealed that a considerable area of roads located in densely built-up areas was covered by debris, resulting in a more than $30 \%$ increase in time for people in the nearby buildings to evacuate. Compared to the scenario without falling debris, the evacuation time with debris was 5\% longer when subjected to MCE (Maximal Considered Earthquake). The proposed failure criterion for masonry infill walls can be employed in debris distribution calculation, which offers technical support for urban planning and evacuation drills.

\footnotetext{
a) Department of Civil Engineering, Tsinghua University, Beijing 100084, China

b) Griffith School of Engineering, Griffith University, Gold Coast Campus, Queensland 4222, Australia
} 


\section{INTRODUCTION}

Masonry infill walls are a type of construction widely used as the envelope of multistory and high-rise buildings in urban areas. Infill walls were observed to have been severely damaged in past earthquakes [1-6], and blocks fell from the attached walls owing to the combined effects of infill wall damage and seismic acceleration. According to field investigations, these masonry infill walls usually have weak boundary connections with the main structure $[7,8]$. This is especially true for the developing countries where quality control of the connection between the infill masonry walls and the main structures is difficult to be ensured. Statistics also show that earthquake-induced falling debris can cause a significant number of casualties [9-11]. Moreover, falling debris can seriously hinder fast emergency evacuations and rescues [12,13]. For people living in densely built-up areas, the presence of debris may increase the total evacuation time up to $30 \%$ [14]. Therefore, it is necessary to conduct a comprehensive research to examine the impact of falling debris of masonry infill walls and the associated influencing factors. In addition, debris distribution and its impact on pedestrian evacuations must be quantified for better disaster management.

There are some existing studies on the falling debris of masonry infill walls. For instance, $\mathrm{Xu}$ et al. [15] predicted the distribution of falling debris from tall buildings. Their study assumed that when the drift ratio of a masonry infill wall exceeded a certain value, cracking of the wall and falling of debris were triggered. The failure criteria for nonstructural components proposed in ASCE-07 [16] was adopted in their work, in which different nonstructural components had their own damage criteria. Liu et al. [17] analyzed the falling debris of indoor partition walls and suspended ceilings based on the fragility curves of the nonstructural components. In Liu et al.'s work [17], the drift ratio was also used as the failure criterion. Lu et al. [14] selected two drift ratio limits for masonry infill walls to calculate and compare debris distributions under different scenarios. Review of literature indicates that the existing studies mainly adopted the drift ratio limit as the failure criterion for a masonry infill wall. It should be noted that the out-of-plane acceleration and height-to-thickness ratio of walls also have some impact on the damage of masonry infill walls and falling debris. As such, the existing failure criteria require further development and improvement.

The test apparatus for a pseudo-static experiment is relatively simple. Therefore, pseudostatic experiments are widely employed to study the behavior of masonry infill walls. Loaddisplacement behaviors of unreinforced masonry walls were obtained through displacement- 
controlled lateral loading in Heydariha et al.'s work [18]. In order to evaluate the influence of the in-plane damage on the out-of-plane behavior of infill walls, cyclic in-plane tests were first carried out and out-of-plane tests were subsequently performed in Angel et al.'s work [19]. Furtado et al. [20] applied the out-of-plane monotonic and cyclic loading on three infill panels to study the influence of in-plane drifts on their out-of-plane performances. In addition, airbag testing was adopted to apply out-of-plane distributed surface loads [21-23]. In the abovementioned experiments, the in-plane damage of masonry infill walls was predetermined before performing the out-of-plane tests. For masonry infill walls weakly connected to the main structure, the infill block failure normally takes the form of combined effects of the out-of-plane acceleration and the in-plane drift. However, previous studies, dealing with the in-plane and out-of-plane loading procedures separately, cannot fully represent such combined effects. Many researchers also conducted shaking table tests to study the seismic performance of masonry infill walls [24-26]. Based on the tests of four multi-wythe walls, Meisl et al. [24] investigated the influence of the ground motion and the construction quality on masonry infill walls. Through the shaking table tests of three masonry infill walls, Tu et al. [7] found that the thickness/slenderness of the walls had a significant influence on the out-of-plane strength and stiffness, which led to a proposed analytical model accounting for the out-of-plane behavior of masonry walls. It is well recognized that the dynamic and spatial effects of ground motions can be simulated through shaking table tests. Nevertheless, a large number of infill wall specimens are required to establish the failure criteria, and numerous factors need to be determined. This makes the shaking table tests too complicated and expensive to perform this task.

In view of the research gaps described above, a pseudo-static test apparatus considering both the in-plane drift ratio and out-of-plane acceleration is designed in this work. Masonry infill wall specimens with different height-to-thickness ratios and out-of-plane accelerations are tested, and a new failure criterion for predicting the percentage of falling area of the infill wall is proposed based on the experimental results. Employing this criterion, the Tsinghua University campus is selected to perform a case study, by which the earthquake-induced debris distribution is demonstrated and the impact of falling debris on pedestrian evacuation is also analyzed. 


\section{EXPERIMENTAL RESEARCH}

90

91

92

93

94

95

96

97

98

99

100

101

102

103

104

105

106

107

\subsection{Experimental Design}

The in-plane stiffness of a masonry infill wall is much larger than its out-of-plane stiffness. Cracking of an infill wall is induced by the in-plane deformation, and subsequently infill blocks will fall from the wall due to the out-of-plane acceleration, resulting in falling debris. To accurately replicate the cracks in the wall and the falling debris subject to seismic loading, a new experimental method for earthquake-induced falling debris from a masonry infill wall is proposed herein.

\subsubsection{Design of specimens}

Owing to their low density and outstanding soundproofing performance, autoclaved aerated concrete blocks are widely used in the infill walls of buildings [27-30]. These kinds of solid blocks were also selected to build the infill wall specimens. The nominal size of the main blocks was $400 \mathrm{~mm} \times 250 \mathrm{~mm}$, while the sizes of the auxiliary blocks were $200 \mathrm{~mm} \times$ $250 \mathrm{~mm}$ and $400 \mathrm{~mm} \times 100 \mathrm{~mm}$. The standard thickness of the infill walls used in buildings normally varies from $100 \mathrm{~mm}$ to $240 \mathrm{~mm}$ [31-33]. To cover this practical range, two types of specimens with different wall thicknesses (i.e., $100 \mathrm{~mm}$ and $200 \mathrm{~mm}$ ) were designed to consider the influence of the height-to-thickness ratios. The size of the two infill wall specimens were $1600 \mathrm{~mm} \times 1600 \mathrm{~mm} \times 100 \mathrm{~mm}($ Fig. 1a) and $1600 \mathrm{~mm} \times 1600 \mathrm{~mm} \times 200$ mm (Fig. 1b), respectively.
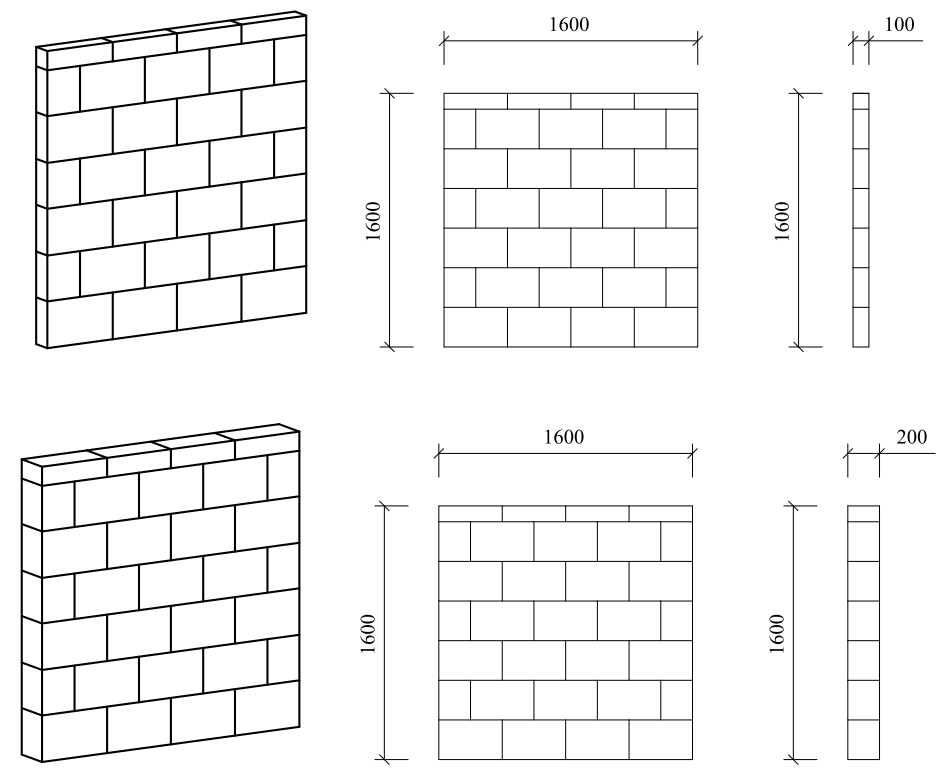
Figure 1. Specimens of masonry infill walls (unit: mm). (a) $100 \mathrm{~mm}$ in thickness. (b) $200 \mathrm{~mm}$ in thickness.

110

\subsubsection{Test setup}

A specialized pseudo-static loading apparatus is designed in this work, taking into 113 account both the in-plane drift ratio and the out-of-plane acceleration. This apparatus is 114 assembled using a steel frame and two concrete supports. The steel frame consists of two 115 steel columns connecting to two steel beams with hinges, as shown in Fig. 2a. The steel 116 frame serves as a structural frame that restrains the exterior infill wall in real buildings. The 117 bottom of the steel frame is bolted to the two concrete blocks which are fixed to the 118 laboratory strong floor. The masonry infill wall specimen is attached to the steel frame with mortar, ensuring the deformation compatibility of the infill wall and the frame. A cyclic load

120 is horizontally applied to the specimen with a $200-\mathrm{kN}$ actuator, which is connected to the 121 upper steel beam. When subjected to the horizontal loads, the initially rectangular-shaped steel frame deforms to a parallelogram. The infill wall specimen correspondingly deforms, which simulates the deformation of an exterior infill wall owing to inter-story drift during an 124 earthquake.
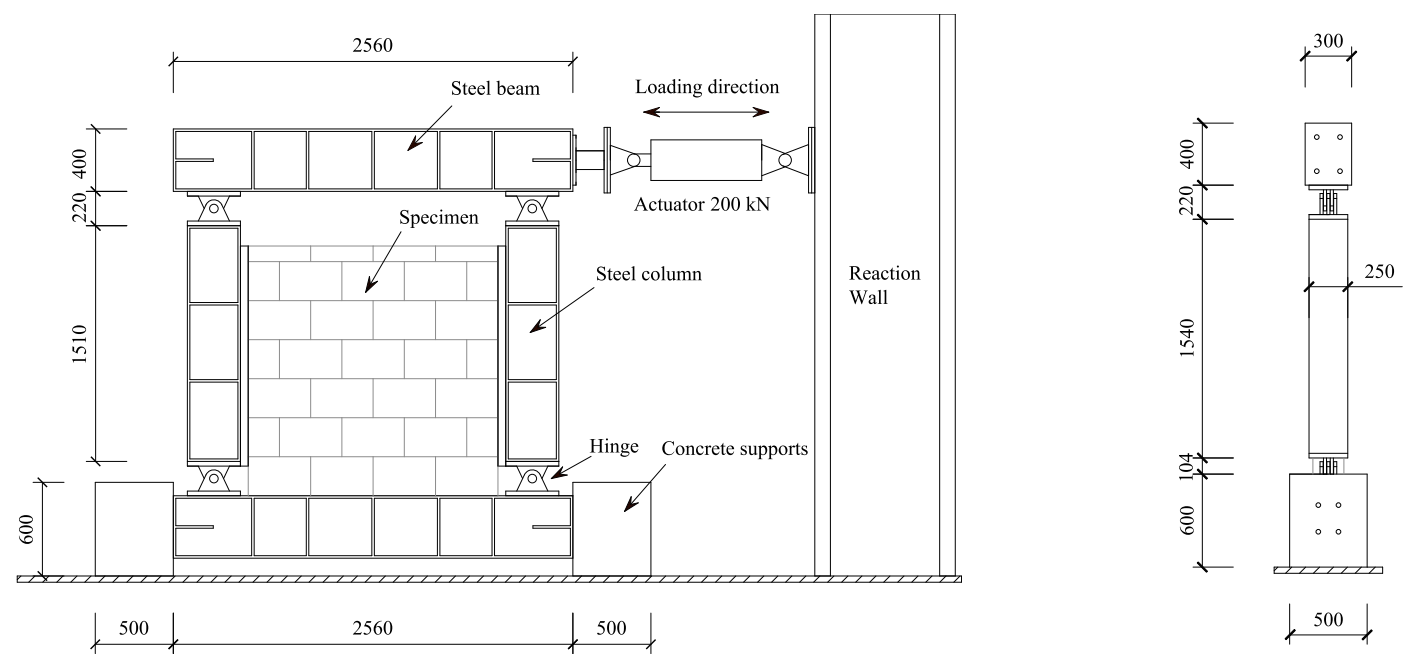

125

126

127

128

129

130

131

Figure 2. Loading apparatus (unit: mm). (a) Front view. (b) Side view.

To simulate the out-of-plane acceleration on the masonry infill wall during an earthquake, the steel frame is mounted to the concrete supports at different tilting angles. The acceleration component of gravity of the tilted infill wall represents the out-of-plane acceleration during an earthquake. A total of five pairs of concrete supports are designed for the experiment (i.e., 10 supports in total), with detailed bolt positions shown in Fig. 3 
132 representing five different titling angles $\left(0^{\circ}, 15^{\circ}, 30^{\circ}, 45^{\circ}\right.$, and $\left.60^{\circ}\right)$ (Fig. 4). The out-of-plane 133 accelerations corresponding to the five angles are $0.0 \mathrm{~g}, 0.26 \mathrm{~g}, 0.50 \mathrm{~g}, 0.70 \mathrm{~g}$, and $0.87 \mathrm{~g}$.

134 Consequently, ten specimens were tested with two different thicknesses (i.e., $100 \mathrm{~mm}$ and $135200 \mathrm{~mm}$ ) and five tilting angles. During the experiment, the out-of-plane tilting angle 136 maintained constant throughout.

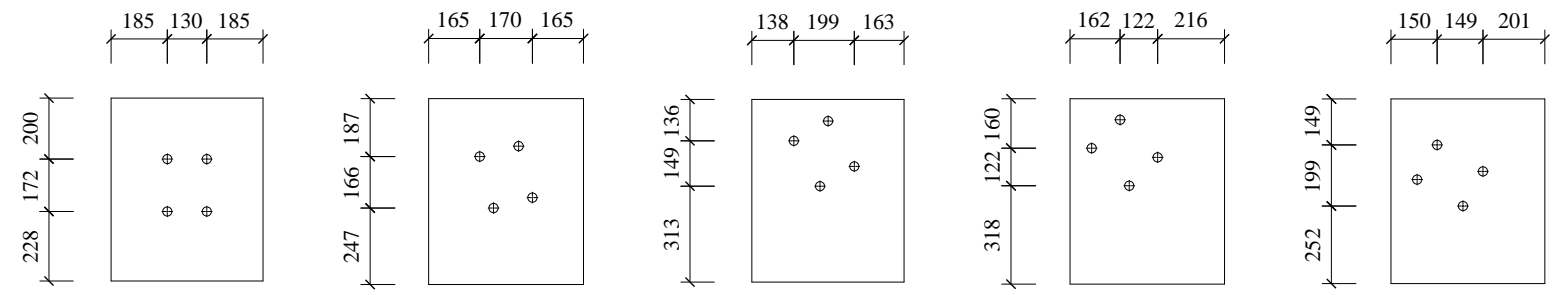

137 Figure 3. Side view of concrete supports with different bolt positions (unit: $\mathrm{mm}$ ). (a) $0^{\circ}$. (b) $15^{\circ}$. (c) $13830^{\circ}$. (d) $45^{\circ}$. (e) $60^{\circ}$.

139

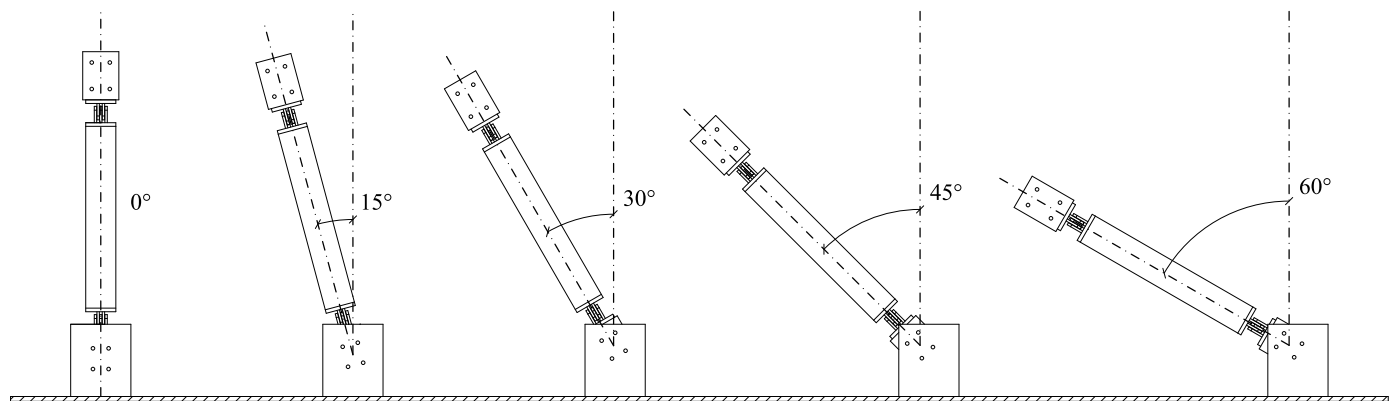

140 Figure 4. Side view of steel frame at different tilting angles.

141

142

\subsubsection{Loading protocol}

143 A pseudo-static in-plane loading procedure with a 24-cycle displacement control was 144 applied to the specimens. For each cycle, the same displacement was repeated twice [34], as 145 shown in Fig. 5.

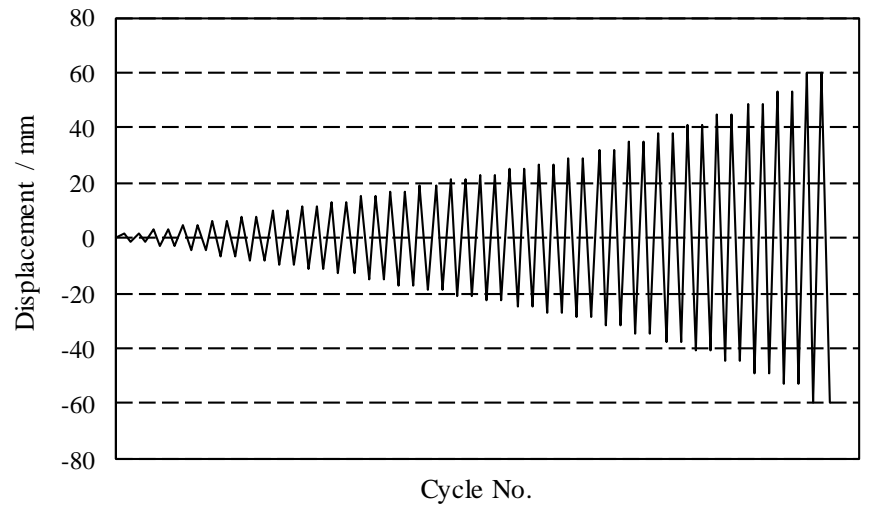

146 Figure 5. Loading protocol. 


\subsection{Experimental Observations and Results}

149 Cracks occurred in the infill walls under the in-plane shear deformation during the 150 experiment. When the tilting angles of the infill wall were $15^{\circ}$ and $30^{\circ}$, several inclined 151 cracks were unidirectionally aligned (Fig. 6). For the tilting angles of $45^{\circ}$ and $60^{\circ}$, major

152 cracks were mostly crossed (Fig. 7). With an increase in deformation, these cracks became 153 wider and more cracks were observed. When the tilting angle was $0^{\circ}$ (i.e., no out-of-plane 154 acceleration), no matter how severely the specimen was damaged, the infill blocks did not 155 fall from the wall. In contrast, when the specimen tilted, the blocks fell progressively after 156 cracking of the infill wall.
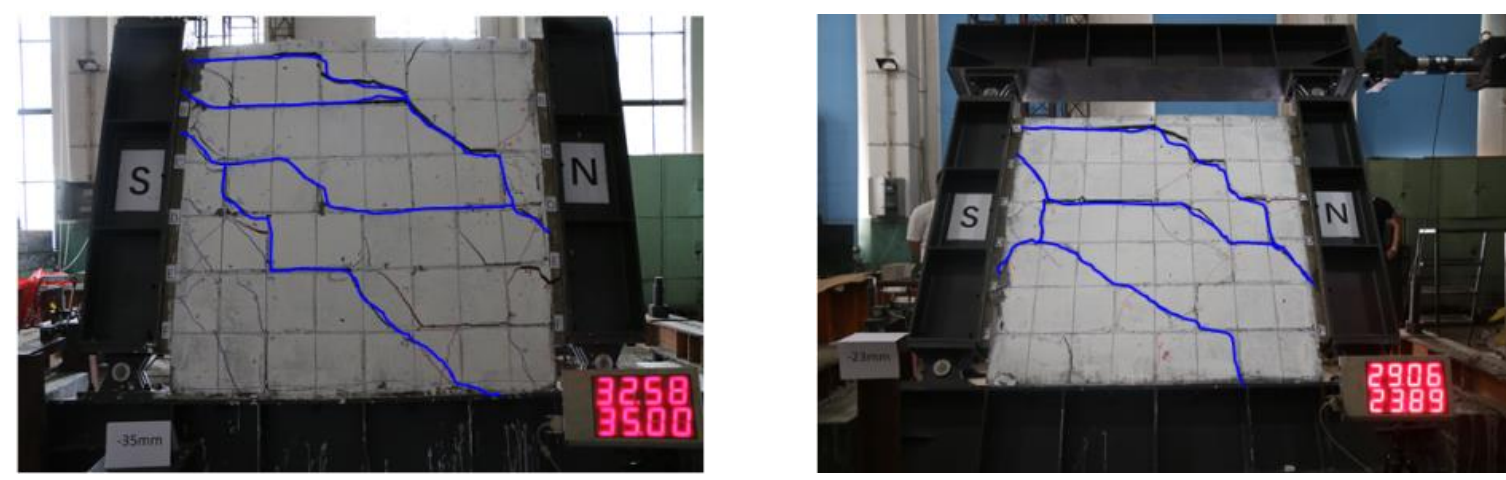

157 Figure 6. Specimens with unidirectional inclined cracks. (a) Tilting angle $15^{\circ}$. (b) Tilting angle $30^{\circ}$. 158
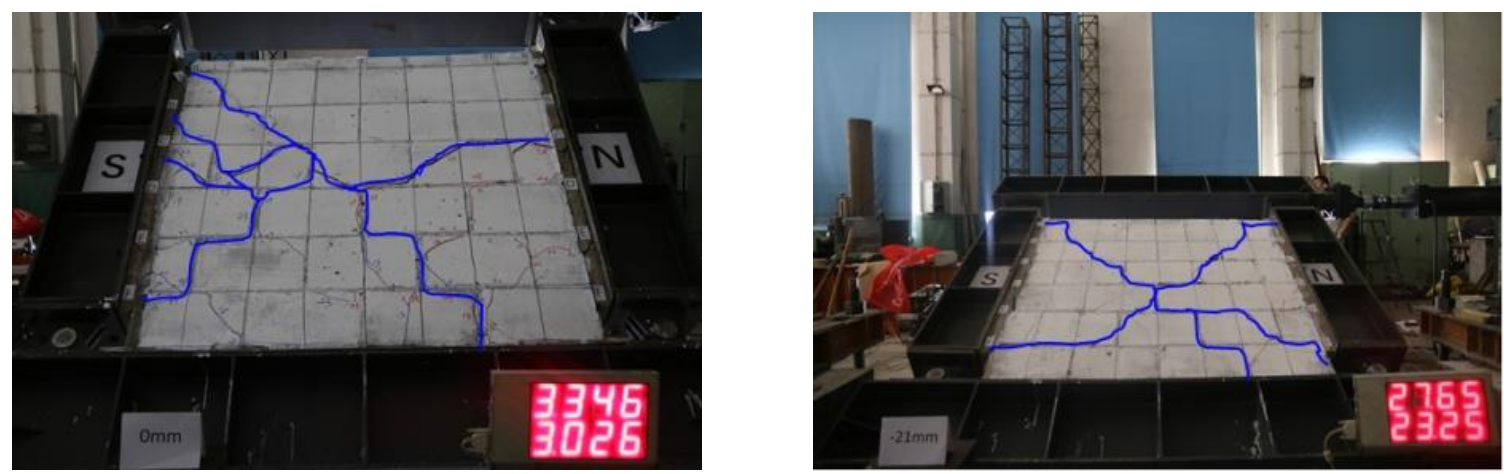

Figure 7. Specimens with crossed cracks. (a) Tilting angle $45^{\circ}$. (b) Tilting angle $60^{\circ}$.

Varying damage states of the 100-mm and 200-mm-thick infill wall specimens with 162 different drift ratios are summarized in Tables 1 and 2, respectively. When the drift ratio 163 reached $1 / 75$, the blocks started to fall from the $100-\mathrm{mm}$-thick infill wall. When the drift ratio 164 reached 1/50, falling blocks were observed from three 100-mm-thick specimens. By contrast, 165 for the 200-mm-thick infill wall, only when the drift ratio reached 1/50 and the specimen was 
166 at the largest tilting angle (i.e., 0.87-g out-of-plane acceleration) did the blocks begin to fall,

167 while the other three specimens did not experience falling blocks. This comparison indicated

168 that, subjected to the same out-of-plane acceleration, the 100 -mm-thick infill wall specimens

169 were more prone to suffer from falling debris than the 200 -mm-thick infill wall specimens. In

170 addition, more blocks fell from the 100-mm-thick specimens when subjected to the same drift

171 ratio and out-of-plane acceleration. In summary, infill blocks fell earlier and the falling area

172 was larger for a thinner infill wall with larger tilting angle.

173 Table 1. Damage states of 100-mm-thick infill wall specimens

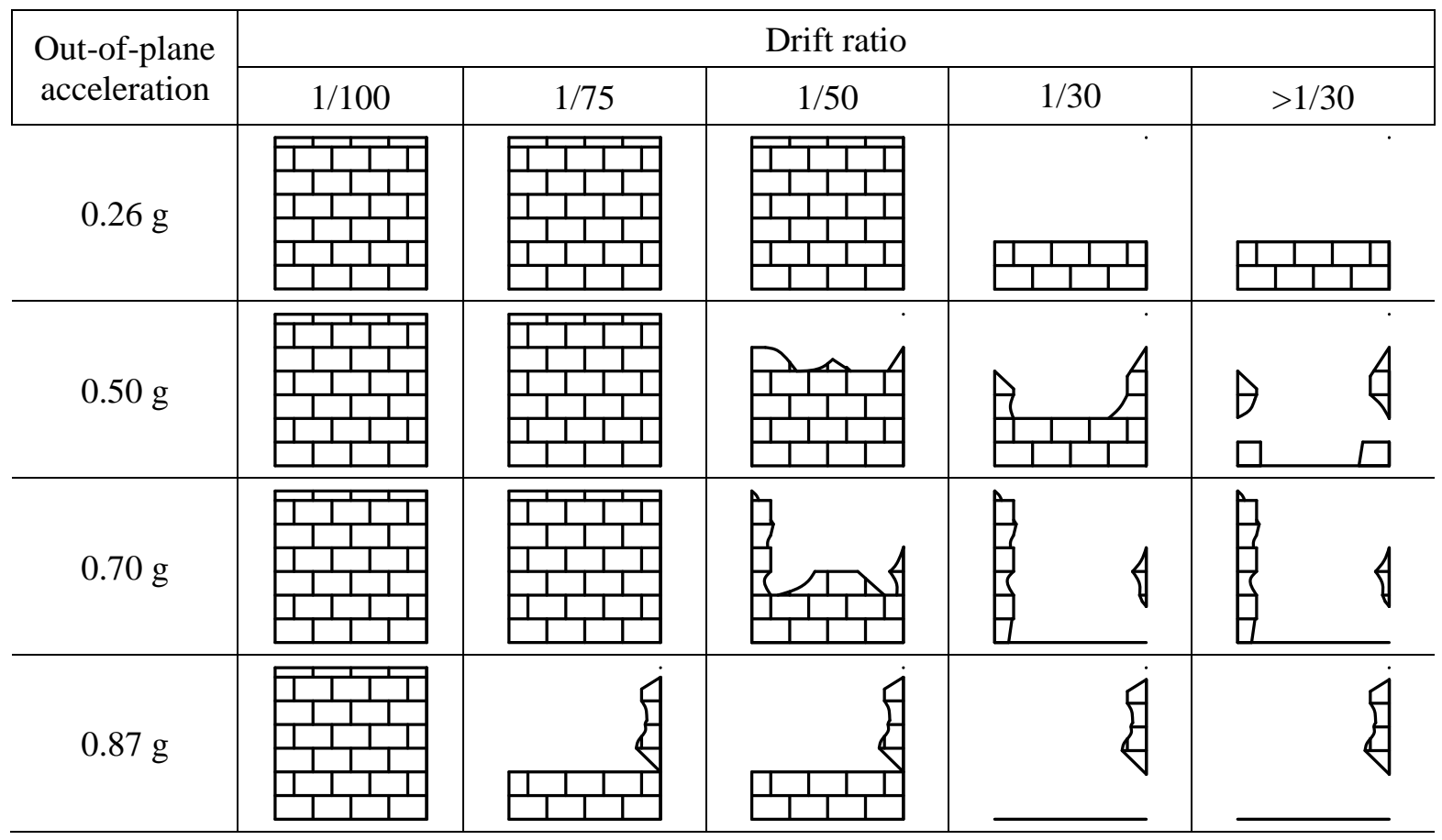

174

175 Table 2. Damage states of 200-mm-thick infill wall specimens

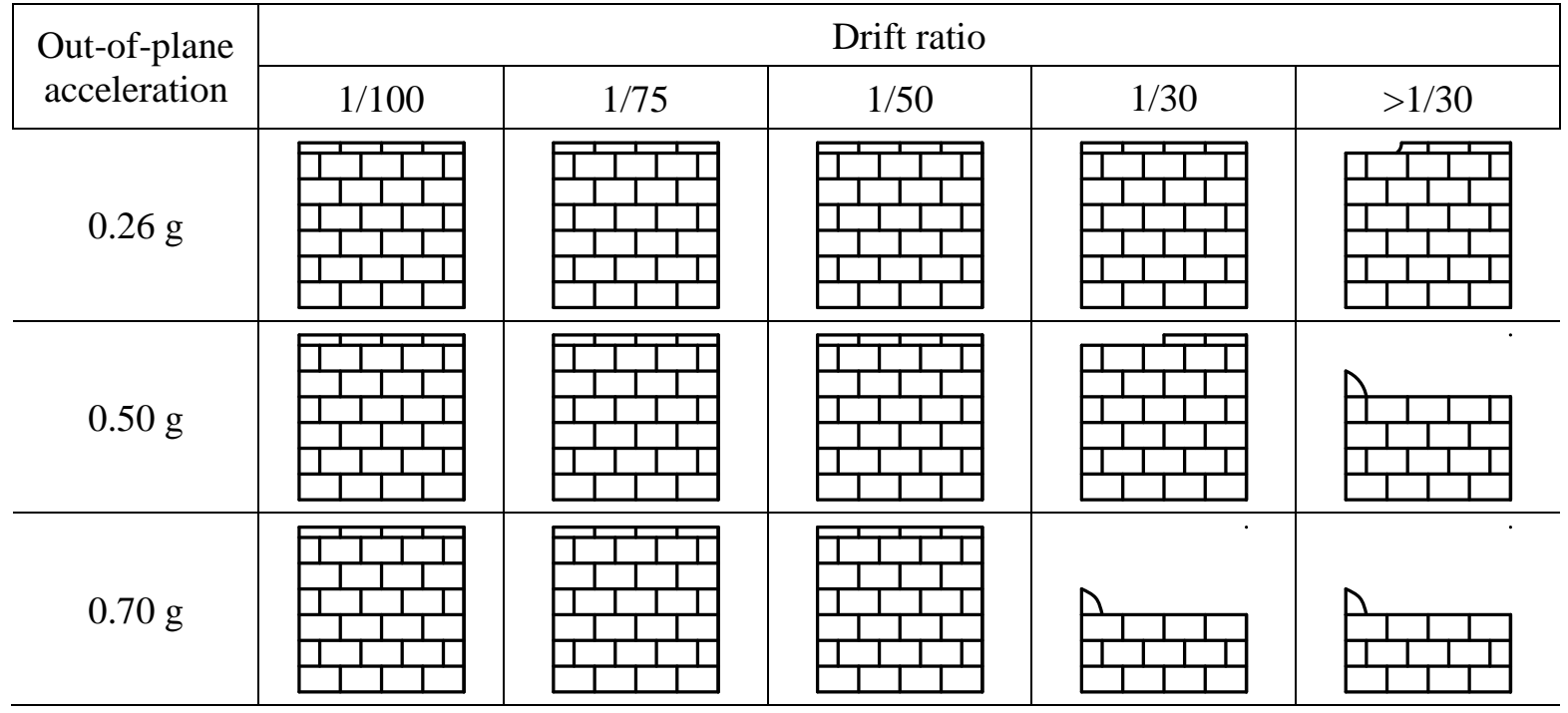


$0.87 \mathrm{~g}$
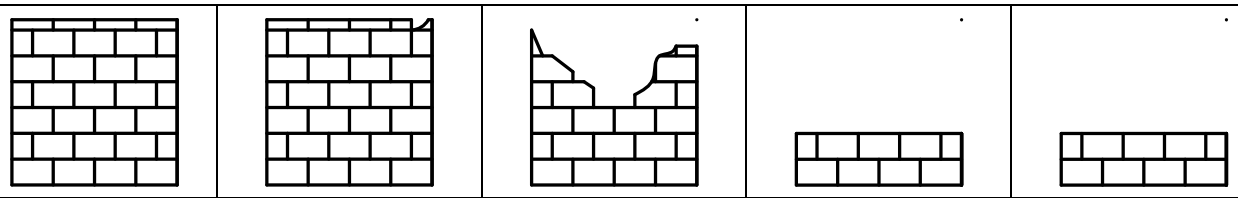

176

177

178

179

180

181

182

183

184

185

186

187

188

189

190

191

192

193

194

The percentage of falling area of the infill wall can be obtained by dividing the total area of falling blocks by the total area of the infill wall. The experimental results under different out-of-plane accelerations and drift ratios are listed in Table 3.

Table 3. Percentages of falling areas of infill wall specimens

\begin{tabular}{c|c|c|c|c|c|c|c|c|c|}
\hline \multirow{2}{*}{$\begin{array}{c}\text { Out-of-plane } \\
\text { acceleration }\end{array}$} & \multicolumn{8}{|c|}{ Drift ratio } \\
\cline { 2 - 11 } & $1 / 100$ & $1 / 80$ & $1 / 60$ & $1 / 50$ & $1 / 40$ & $1 / 35$ & $1 / 30$ & $>1 / 30$ \\
\hline \multirow{3}{*}{$\begin{array}{c}100-m m \\
\text { infill } \\
\text { wall }\end{array}$} & $0.26 \mathrm{~g}$ & 0 & 0 & 0 & 0 & $6.0 \%$ & $47.4 \%$ & $68.8 \%$ & $68.8 \%$ \\
\cline { 2 - 11 } & $0.50 \mathrm{~g}$ & 0 & 0 & 0 & $32.4 \%$ & $60.1 \%$ & $60.1 \%$ & $88.7 \%$ & $88.7 \%$ \\
\cline { 2 - 11 } & $0.70 \mathrm{~g}$ & 0 & 0 & $38.2 \%$ & $52.5 \%$ & $87.3 \%$ & $87.3 \%$ & $87.3 \%$ & $87.3 \%$ \\
\hline & $0.87 \mathrm{~g}$ & 0 & $48.1 \%$ & $62.5 \%$ & $62.5 \%$ & $93.8 \%$ & $93.8 \%$ & $93.8 \%$ & $93.8 \%$ \\
\hline \multirow{3}{*}{$\begin{array}{c}200-m m \\
\text { infill } \\
\text { wall }\end{array}$} & $0.26 \mathrm{~g}$ & 0 & 0 & 0 & 0 & 0 & 0 & 0 & $2.1 \%$ \\
\cline { 2 - 10 } & $0.50 \mathrm{~g}$ & 0 & 0 & 0 & 0 & 0 & 0 & $3.1 \%$ & $36.5 \%$ \\
\cline { 2 - 10 } & $0.70 \mathrm{~g}$ & 0 & 0 & 0 & 0 & $0.3 \%$ & $0.3 \%$ & $52.1 \%$ & $52.1 \%$ \\
\hline & $0.87 \mathrm{~g}$ & 0 & 0 & $0.3 \%$ & $33.2 \%$ & $68.8 \%$ & $68.8 \%$ & $68.8 \%$ & $68.8 \%$ \\
\hline
\end{tabular}

\subsection{Prediction Model for Falling Area of Infill Walls}

For a masonry infill wall without out-of-plane acceleration (which means that the test specimen stood vertically), when the drift ratio exceeded $1 / 30$, the test specimen was severely damaged. Some blocks were detached from others because of large cracks in the wall. However, these detached blocks were still interlocked with the surrounding blocks. Given nil out-of-plane resultant force, these blocks did not fall. Consequently, two conditions are required for the blocks to fall: (1) cracks continuously develop through the masonry infill wall, and (2) the out-of-plane resultant forces of the blocks are larger than the friction forces between the blocks. The falling area of the infill wall is related to its drift ratio, out-of-plane acceleration, and height-to-thickness ratio. According to the experimental results presented in Table 3, a logistic regression function is adopted leading to the proposed prediction model of the falling area, which is expressed as:

$$
A_{\text {debris }}=A_{\text {wall }}\left(\frac{\lambda_{\max }}{1+e^{9.87 \times(1-\gamma \Delta)}}\right),
$$


195

196

197

where $A_{\text {debris }}$ and $A_{\text {wall }}$ represent the debris falling area and the total area of the masonry infill wall, respectively. $\lambda_{\max }$ represents the maximum percentage of the falling area, $\lambda_{\max }=1-$ $e^{-0.15 \eta} . \eta$ denotes the height-to-thickness ratio, $\Delta$ stands for the drift ratio, and $\gamma$ is the correction factor, which is calculated using Eq. (2).

$$
\gamma=183.1 \alpha^{3}-86.6 \alpha^{2}-12.46 \alpha^{2} \eta-15.38 \alpha+13.36 \alpha \eta,
$$

where $\alpha=a_{\max } / g$, and $a_{\max }$ denotes the maximum out-of-plane acceleration of the infill wall, and $g$ represents the acceleration of gravity.

The comparison of experimental results and predictions of Eq. (1) is shown in Fig. 8. The proposed model can be used as the failure criterion of masonry infill walls to calculate the debris distribution of buildings.

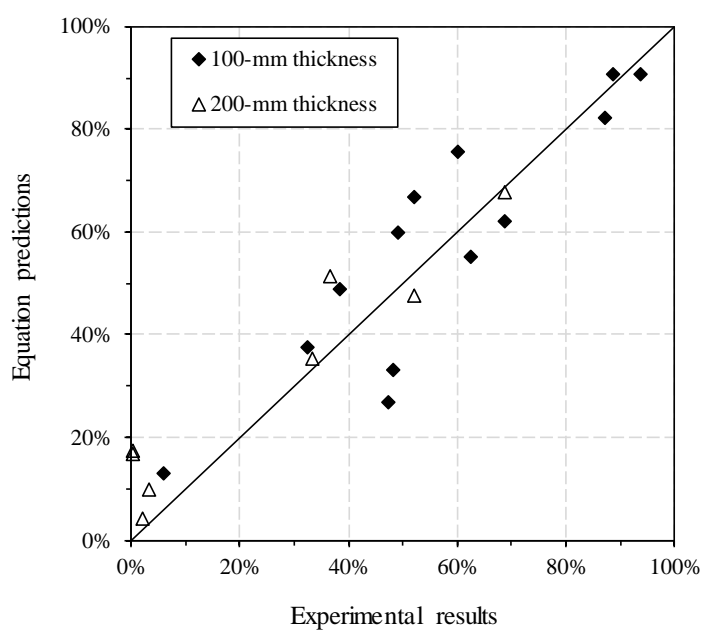

Figure 8. Comparison of experiment results and predictions of Eq. (1) on falling area

3 CASE STUDY OF PEDESTRIAN EVACUATION CONSIDERING THE INFLUENCE OF FALLING DEBRIS

\subsection{Brief Introduction of Evacuation Simulation Methodology}

Falling debris from buildings hinders fast pedestrian evacuation. To quantify the

211 influence of the falling debris, the framework of pedestrian evacuation simulation proposed 212 by $\mathrm{Lu}$ et al. [14] is adopted herein (Fig. 9). This framework consists of four modules: (1) 213 database of regional buildings and roads, (2) nonlinear time-history analysis of regional 214 buildings, (3) prediction of falling debris distribution, and (4) pedestrian evacuation 215 simulation considering the influence of the falling debris. Details of the methodology can be 216 found in Lu et al. [14], and four modules are briefly introduced as follows. 


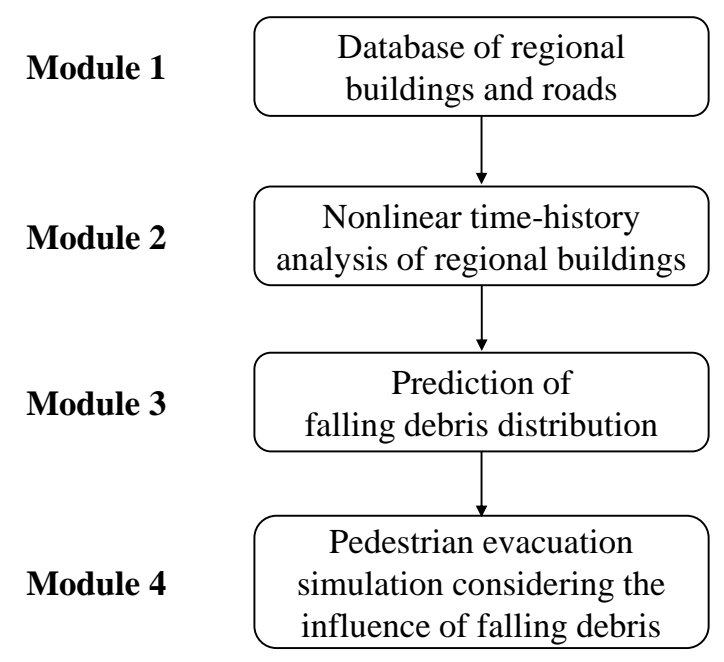

217 Figure 9. The framework of pedestrian evacuation simulation [14].

218
In Module 1, a database of regional buildings and roads needs to be established first. This database contains building information, road information, emergency shelter locations, and population distribution. The attribute data of buildings (e.g., building height, number of stories, and structural type) can be obtained from a city database [35] or field investigation [36]. The locations of buildings and emergency shelters, as well as the road information, can be obtained from Google Maps [37] or OpenStreetMap [38].

In Module 2, nonlinear multi-degree-of-freedom models (including the multiple degreeof-freedom (MDOF) shear model for multi-story frame and masonry structures, and the MDOF flexural-shear model for tall buildings) are adopted to complete the regional building modeling [39,40] through a nonlinear time-history analysis, by which satisfactory computational accuracy and efficiency can be achieved. Subsequently, time histories of the displacement, velocity, and acceleration for each story of each building are obtained.

In Module 3, when a masonry infill wall reaches a certain drift ratio and out-of-plane acceleration, crack starts to develop and falling debris is induced. It should be noted that, due to considerable deviations of the drift ratio limits of masonry infill walls, a parametric discussion was conducted in Lu et al.'s work [14]. As the failure criterion for masonry infill walls has been proposed in Section 2, it is thus adopted herein to determine the percentage of falling area of the infill wall. Subsequently, based on the debris distribution models of each floor [14], the hazard range of falling debris and the debris coverage percentages on roads can be identified. 
In Module 4, the simulation of pedestrian evacuation, taking into account the falling debris, covers two parts: construction of evacuation environment and modeling of human behavior. The evacuation environment can be determined by employing the road information 242 and the locations of buildings and emergency shelters. Debris distribution obtained in 243 Module 3 will also be employed in the evacuation environment. When the pedestrians pass 244 through the areas covered by falling debris, their moving speed will change, which can be 245 determined by the pedestrian speed models considering debris proposed by Lu et al. [14]. 246 According to the experiment of the pedestrian movement [14], it is found that when the percentage of debris coverage on the road reaches $25 \%$, pedestrians can hardly pass through.

248 Therefore, these roads are set as blocked areas. Meanwhile, roads with the percentage of 249 debris coverage being lower than 25\% are set as reduced-speed areas. After establishing the evacuation scenario, simulation of pedestrian evacuation can then be performed by using the 251 widely used evacuation software, Viswalk [41,42].

\subsection{Introduction of the Case Study Area}

253 The teaching areas of Tsinghua University consists of 15 buildings, most of which are 254 teaching buildings and research laboratories. This area houses a significant number of 255 students and academics during lecture and tutorial times. Therefore, this area is selected to 256 perform a case study of the earthquake-induced debris calculation and pedestrian evacuation. 257 A playground located in the northeast of the teaching area is designated as the emergency 258 shelter [43,44]. The building occupants are required to be evacuated to the playground during emergencies. The teaching area, shown in Fig. 10, has a gross area of approximately 0.22

$260 \mathrm{~km} 2$, where the blue slashes polygons denote the buildings, the solid green areas denote the 261 roads, and the green rectangle with grids denotes the emergency shelter. 


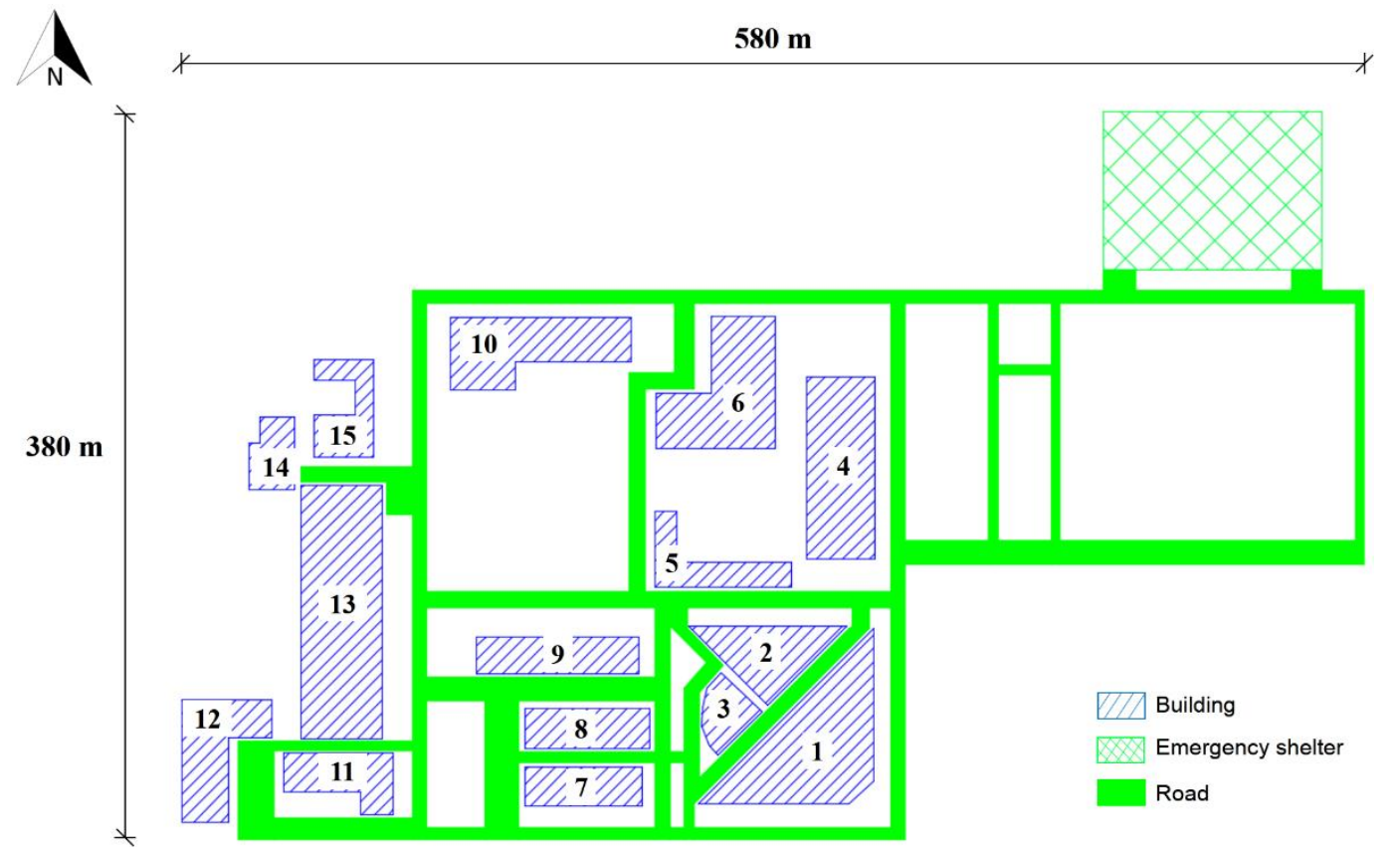

262 Figure 10. Schematic diagram of teaching areas.

264 FEMA P-58 defines the number of people in buildings with different occupancies [45].

265 Consequently, the population in each building can be predicted using FEMA P-58 and 266 building attribute data. The basic information of the buildings is given in Table 4.

267 Table 4. Basic information of the buildings

\begin{tabular}{c|c|c|c}
\hline No. & Number of stories & Building occupancy & Population \\
\hline 1 & 5 & Education & 1190 \\
\hline 2 & 9 & Education & 740 \\
\hline 3 & 4 & Education & 360 \\
\hline 4 & 4 & Research laboratories & 265 \\
\hline 5 & 2 & Research laboratories & 75 \\
\hline 6 & 1 & Research laboratories & 70 \\
\hline 7 & 3 & Education & 450 \\
\hline 8 & 3 & Education & 490 \\
\hline 9 & 5 & Education & 590 \\
\hline 10 & 4 & Commercial office & 430 \\
\hline 11 & 5 & Education & 660 \\
\hline 12 & 2 & Education & 480 \\
\hline 13 & 2 & Research laboratories & 235 \\
\hline 14 & 5 & Research laboratories & 125 \\
\hline 15 & 2 & Research laboratories & 70 \\
\hline
\end{tabular}


According to the Chinese Code for Seismic Design of Buildings [46], this area has an eight-degree seismic design intensity. The peak ground acceleration (PGA) is $200 \mathrm{~cm} / \mathrm{s}^{2}$ for a

271 Design Basis Earthquake (DBE) with a return period of 475 years, and the PGA is $400 \mathrm{~cm} / \mathrm{s}^{2}$

272 for a Maximum Considered Earthquake (MCE) with a return period of 2475 years.

273

274

275

276

277

278

279

280

281

282

283

284

285

286

287

288

289

290

291

292

293

294

295

296

297

The widely used El-Centro ground motion record is selected as a typical ground motion input. Three evacuation scenarios are then established herein:

Scenario 1: Pedestrian evacuation scenario without debris;

Scenario 2: Pedestrian evacuation scenario with debris, where the peak ground acceleration is scaled to $200 \mathrm{~cm} / \mathrm{s}^{2}$; and

Scenario 3: Pedestrian evacuation scenario with debris, where the peak ground acceleration is scaled to $400 \mathrm{~cm} / \mathrm{s}^{2}$.

Note that according to the Chinese seismic design codes [46], the building should be prevented from collapse when subjected to DBE or MCE. As a consequence, no collapsed building is considered in this simulation.

When calculating the debris distribution, Eq. (1) proposed in Section 2 is adopted as the failure criterion for the masonry infill walls. The height-to-thickness ratio of an infill wall is determined according to the design information. The other two parameters in Eqs. (1) and (2), i.e., the drift ratio and out-of-plane acceleration, can be acquired from the time history analysis results.

\subsection{Simulation Results and Discussion}

The debris distributions of the two evacuation scenarios (2 and 3) are illustrated in Fig. 11. The red polygons denote the blocked areas, where pedestrians cannot pass through; the yellow polygons represent the reduced-speed areas, suggesting reduced speed of people when passing through owing to falling debris. Compared to Scenario 1, where there is no debris, the evacuation of people in Scenario 2 is seldom influenced by falling debris. As the figures reveal, in Scenario $2\left(\mathrm{PGA}=200 \mathrm{~cm} / \mathrm{s}^{2}\right)$, only $1-\mathrm{m}$ wide reduced-speed areas exist around Building \#1, and there is no debris around the other buildings. However, in Scenario 3 (PGA $=400 \mathrm{~cm} / \mathrm{s}^{2}$ ), some areas of the $7-\mathrm{m}$ wide road adjacent to Building \#1, Building \#2, and Building \#3 are covered by falling debris. The blocked width of Road A is $3 \mathrm{~m}$, while that of Road B is $5 \mathrm{~m}$, which indicates that these two roads are at higher risk from falling debris. In 
addition, a 2-m wide passage of Road C is blocked. There are no blocked areas on other

300 roads in Scenario 3, but the reduced-speed areas are more than those in Scenario 2, where the 301 pedestrians' speed are affected.
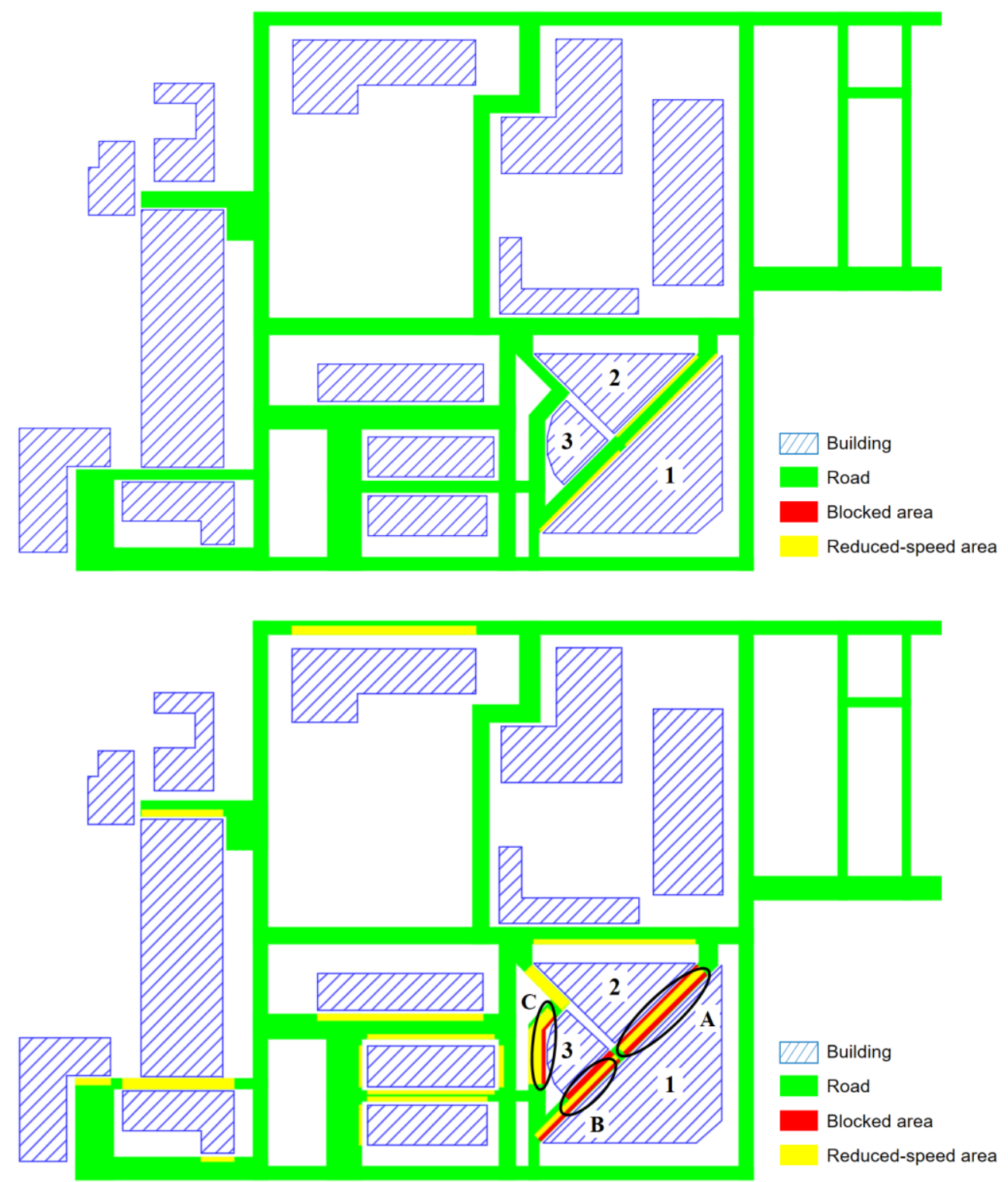

302

303

304

305

306

307

308

309

Figure 11. Debris distribution. (a) $P G A=200 \mathrm{~cm} / \mathrm{s}^{2}$ (Scenario 2). (b) $P G A=400 \mathrm{~cm} / \mathrm{s}^{2}$ (Scenario 3).

Pedestrian evacuations under the abovementioned three scenarios are simulated. The falling debris mainly cover the roads around Building \#1, Building \#2, and Building \#3, and the number of occupants in these densely built-up areas accounts for more than $36 \%$ of the entire teaching area. Therefore, the evacuation process for these people is analyzed in particular, and the evacuation outcomes are shown in Fig. 12. For occupants in Building \#1 and Building \#3, the average evacuation distances in the three scenarios are almost the same 
310 (Fig. 12a). The reason is that the roads in these three scenarios are not entirely blocked 311 despite the existence of falling debris (Fig. 11). Consequently, people do not need to detour. 312 As Fig. 11a shows, in Scenario 2, the roads around Building \#1 only have a 1-m wide 313 blocked area, and there is no debris around Building \#3, which has almost no effect on the 314 pedestrian evacuation. Therefore, the average evacuation times in Scenario 1 and Scenario 2 315 are identical for people in Building \#1 and Building \#3. In Scenario 3, there is basically no 316 change in the average evacuation distance, which means that falling debris does not change 317 the original evacuation routes of most pedestrians. However, the presence of falling debris 318 results in a $41 \%$ increase in the average evacuation time for people in Building \#1 and a $31 \%$ 319 increase for people in Building \#3 (Fig. 12b). These increased rates are significant.
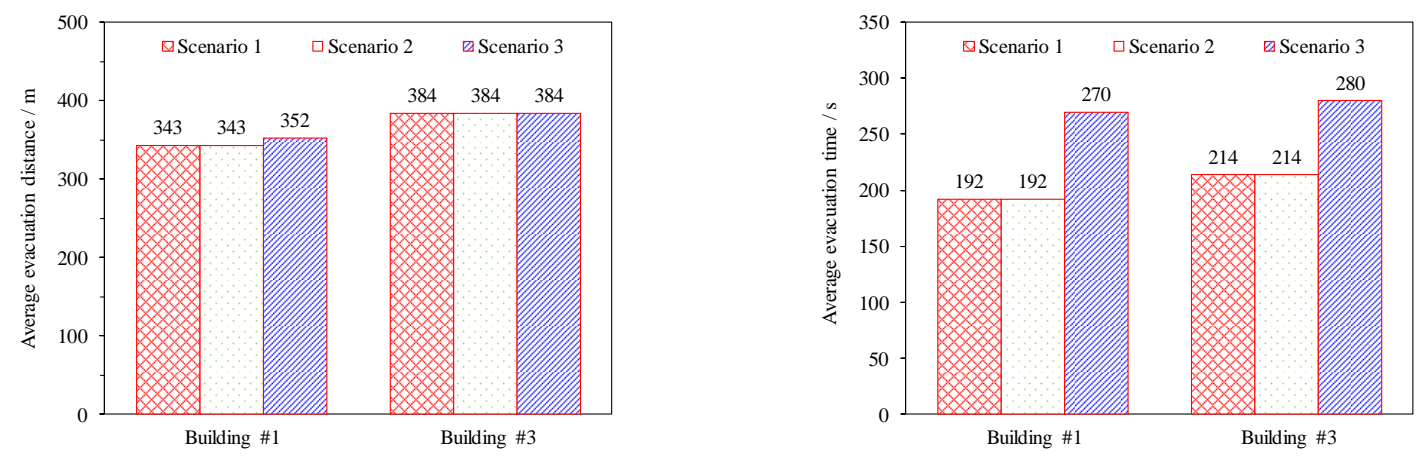

320 Figure 12. Comparison of evacuation outcomes (Building \#1 and Building \#3). (a) Average 321 evacuation distance. (b) Average evacuation time.

The evacuation times of the three scenarios are shown in Table 5 and Fig. 13. It takes 707 324 s for all the people to reach the emergency shelter in Scenario 1 (i.e., without debris). The 325 evacuation time of Scenario 2 (PGA $1 / 4200 \mathrm{~cm} / \mathrm{s} 2)$ is almost equal to that of Scenario 1, 326 which is consistent with the aforementioned analysis of the debris distribution. Compared to 327 Scenario 1, the total evacuation time is approximately 5\% longer in Scenario 3 when 328 subjected to MCE. Similar conclusions can be drawn when considering the clearance time of 329 95\% of the evacuees: the evacuation times of Scenario 1 and Scenario 2 are still close, and 330 that of Scenario 3 increases by approximately $8 \%$ compared to that of Scenario 1.

331 Table 5. Comparison of evacuation time in different scenarios

\begin{tabular}{c|c|c|c|}
\hline No. & Evacuation scenario & $\begin{array}{c}\text { Clearance time } \\
(95 \% \text { evacuees })(\mathrm{s})\end{array}$ & $\begin{array}{c}\text { Total evacuation time } \\
(100 \% \text { evacuees })(\mathrm{s})\end{array}$ \\
\hline 1 & No debris & 565 & 707 \\
\hline 2 & Debris, PGA $=200 \mathrm{~cm} / \mathrm{s}^{2}$ & 568 & 708 \\
\hline 3 & Debris, PGA $=400 \mathrm{~cm} / \mathrm{s}^{2}$ & 609 & 741 \\
\hline
\end{tabular}




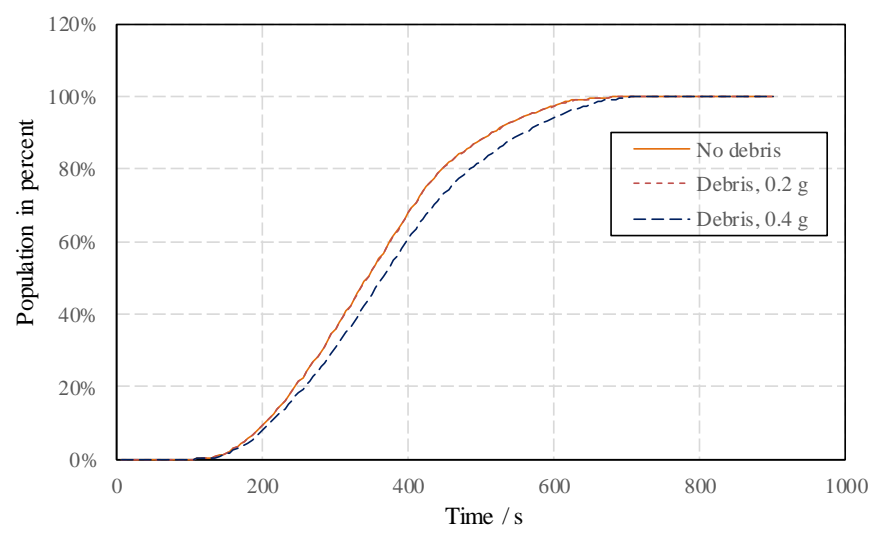

333 Figure 13. Comparison of different evacuation scenarios.

334

335

336

337

338

339

340

The results of this case study reveal that a considerable area of roads located in densely built-up areas is covered by debris, resulting in a significant increase in the evacuation time of people in the nearby buildings. These people are at higher risk during the emergency evacuation. Therefore, when conducting a regional evacuation analysis, we should focus not only on the total evacuation process but also pay more attention to people in densely built-up areas and quantify the influence of falling debris on their evacuation time and distance.

\section{CONCLUSIONS}

In order to study the seismic performance of masonry infill walls and the initiation of falling debris, a new experimental methodology of earthquake-induced debris from masonry infill walls is proposed. This methodology considers the influence of the in-plane drift ratio and the out-of-plane acceleration. Ten infill wall specimens were then tested. Based on the experimental results, a case study of the teaching area on the Tsinghua University campus was selected to perform a seismic debris distribution calculation and pedestrian evacuation simulation. The following conclusions were obtained:

(1) The percentage of falling area of the infill wall is related to its drift ratio, out-of-plane acceleration, and height-to-thickness ratio. Subjected to the same out-of-plane acceleration, the $100-$ mm-thick infill walls are more prone to produce falling debris than the $200-\mathrm{mm}$ thick infill walls. In addition, more blocks fall from the 100-mm-thick walls when subjected to the same drift ratio and out-of-plane acceleration. 
(2) A larger drift ratio, out-of-plane acceleration, and height-to-thickness ratio lead to a 355 higher percentage of falling area. When the out-of-plane acceleration is zero, no falling 356 debris was observed even if the infill wall was severely damaged.

(3) A prediction model of the falling area is proposed based on the experimental results. 358 This can be adopted as the falling criteria for a masonry infill wall and applied for the 359 earthquake-induced debris calculation.

360 (4) The case study shows that the total evacuation time in Scenario 2 is close to that in 361 Scenario 1, and that of Scenario 3 is approximately 5\% longer compared to Scenario 1.

362 (5) When the falling debris does not entirely block a road, the evacuation distance 363 changes little for people in densely built-up areas. However, the presence of large amounts of 364 debris was found to significantly increase the evacuation time. This should be taken into 365 sufficient consideration during evacuation drills and emergency rescue operations.

\section{ACKNOWLEDGEMENTS}

The authors are grateful for the financial support received from the National Natural Science Foundation of China (U1709212).

\section{REFERENCES}

[1] B. Zhao, F. Taucer, T. Rossetto, Field investigation on the performance of building structures during the 12 may 2008 Wenchuan earthquake in China, Eng. Struct. 31 (8) (2009) 1707-1723.

[2] A. Buchanan, D. Carradine, G. Beattie, H. Morris, Performance of houses during the 375 Christchurch earthquake of 22 february 2011, Bull. N. Z. Soc. Earthq. Eng. 44 (4) (2011) 342-357.

[3] X.Z. Lu, L.P. Ye, Y.H. Ma, D.Y. Tang, Lessons from the collapse of typical RC frames in Xuankou school during the great Wenchuan earthquake, Adv. Struct. Eng. 15 (1) (2012) $139-153$.

[4] L. Hermanns, A. Fraile, E. Alarcón, R. Álvarez, Performance of buildings with masonry infill walls during the 2011 Lorca earthquake, Bull. Earthq. Eng. 12 (5) (2014) 19771997. 
382

383

384

385

386

387

388

389

390

391

392

393

394

395

396

397

398

399

400

401

402

403

404

405

406

407

408

409

410

411

[5] D. Dizhur, R.P. Dhakal, J. Bothara, J.M. Ingham, Building typologies and failure modes observed in the 2015 Gorkha (Nepal) earthquake, Bull. N. Z. Soc. Earthq. Eng. 49 (2) (2016) 211-232.

[6] S.C. Dutta, S. Nayak, G. Acharjee, S.K. Panda, P.K. Das, Gorkha (Nepal) earthquake of april 25, 2015: actual damage, retrofitting measures and prediction by RVS for A few typical structures, Soil Dyn. Earthq. Eng. 89 (2016) 171-184.

[7] Y.H. Tu, T.H. Chuang, P.M. Liu, Y.S. Yang, Out-of-plane shaking table tests on unreinforced masonry panels in RC frames, Eng. Struct. 32 (12) (2010) 3925-3935.

[8] S.C. Dutta, P.S. Mukhopadhyay, R. Saha, S. Nayak, 2011 Sikkim earthquake at eastern Himalayas: lessons learnt from performance of structures, Soil Dyn. Earthq. Eng. 75 (2015) 121-129.

[9] C. Peek-Asa, J.F. Kraus, L.B. Bourque, D. Vimalachandra, J. Yu, J. Abrams, Fatal and hospitalized injuries resulting from the 1994 northridge earthquake, Int. J. Epidemiol. 27 (3) (1998) 459-465.

[10] Y.F. Chan, K. Alagappan, A. Gandhi, C. Donovan, Disaster management following the Chi-Chi earthquake in Taiwan, Prehospital Disaster Med. 21 (3) (2006) 196-202.

[11] J. Qiu, G.D. Liu, S.X. Wang, X.Z. Zhang, L. Zhang, Y. Li, D.F. Yuan, Z.H. Yang, J. H. Zhou, Analysis of injuries and treatment of 3401 inpatients in 2008 Wenchuan earthquake-based on Chinese Trauma databank, Chin. J. Traumatol. 13 (5) (2010) 297303.

[12] A. Goretti, V. Sarli, Road network and damaged buildings in urban areas: short and long-term interaction, Bull. Earthq. Eng. 4 (2) (2006) 159-175.

[13] N. Hirokawa, T. Osaragi, Earthquake disaster simulation system: integration of models for building collapse, road blockage, and fire spread, J. Disaster Res. 11 (2) (2016) 175187.

[14] X.Z. Lu, Z.B. Yang, G.P. Cimellaro, Z. Xu, Pedestrian evacuation simulation under the scenario of earthquake-induced falling debris, Saf. Sci. 114 (2019) 61-71.

[15] Z. Xu, X.Z. Lu, H. Guan, Y. Tian, A.Z. Ren, Simulation of earthquake-induced hazards of falling exterior non-structural components and its application to emergency shelter design, Nat. Hazards 80 (2) (2016) 935-950. 
[16] American Society of Civil Engineers (ASCE), Minimum Design Loads for Buildings and Other Structures, vols. 7-10, ASCE, Reston, VA, 2010.

414 [17] Z. Liu, C.C. Jacques, S. Szyniszewski, J.K. Guest, B.W. Schafer, T. Igusa, J. MitraniReiser, Agent-based simulation of building evacuation after an earthquake: coupling human behavior with structural response, Nat. Hazards Rev. 17 (1) (2015) 4015019.

[18] J.Z. Heydariha, H. Ghaednia, S. Nayak, S. Das, S. Bhattacharya, S.C. Dutta,

[22] A. Ghobarah, K. El Mandooh Galal, Out-of-Plane strengthening of unreinforced masonry walls with openings, J. Compos. Constr. 8 (4) (2004) 298-305.

[23] H. Derakhshan, M.C. Griffith, J.M. Ingham, Airbag testing of multi-leaf unreinforced masonry walls subjected to one-way bending, Eng. Struct. 57 (2013) 512-522.

[24] C.S. Meisl, K.J. Elwood, C.E. Ventura, Shake table tests on the out-of-plane response of unreinforced masonry walls, Can. J. Civ. Eng. 34 (11) (2007) 1381-1392.

[25] S. Nayak, S.C. Dutta, Failure of masonry structures in earthquake: a few simple cost effective techniques as possible solutions, Eng. Struct. 106 (2016) 53-67.

[26] S. Nayak, S.C. Dutta, Improving seismic performance of masonry structures with openings by polypropylene bands and L-shaped reinforcing bars, J. Perform. Constr. Facil. 30 (2) (2016), 04015003.

[27] A.A. Costa, A. Penna, G. Magenes, Seismic performance of autoclaved aerated concrete (AAC) masonry: from experimental testing of the in-plane capacity of walls to building response simulation, J. Earthq. Eng. 15 (1) (2011) 1-31. 
[28] J.W. Hu, F. Xu, D.S. Du, S.G. Wang, W.W. Li, Experimental study on shaking table test of full-scale steel frame with embedded autoclaved lightweight concrete wall panels, J. Build. Struct. 39 (6) (2018) 141-148 (in Chinese).

[29] L.H. Xiong, M.K. Luo, G.W. Chen, C. Yang, Experimental study on seismic performance of BFG autoclaved aerated concrete block infilled frame, Earthq. Eng. Eng. Dyn. 38 (3) (2018) 134-141 (in Chinese).

[30] C.P. Chea, X.Z. Lu, Z.B. Yang, Z. Xu, X. Zhang, Experimental research and range of injury risk analysis of earthquake-induced hazard of falling exterior infill walls, J. Nat. Disasters 27 (1) (2018) 17-26 (in Chinese).

[31] A. Hashemi, K.M. Mosalam, Shake-table experiment on reinforced concrete structure containing masonry infill wall, Earthq. Eng. Struct. Dyn. 35 (14) (2006) 1827-1852.

[32] M.R. Wakchaure, S.P. Ped, Earthquake analysis of high rise building with and without infilled walls, Int. J. Eng. Innov. Technol. 2 (2) (2012) 89-94.

[33] X.J. Zhou, Z.X. Li, D.D. Xu, X.L. Jiang, Experiment on seismic behavior of flexible connection masonry infilled frame structure, J. Tianjin Univ. 48 (2) (2015) 155-166 (in Chinese).

[34] Ministry of Housing and Urban-Rural development of the People's Republic of China (MOHURD), Specification for Seismic Test of Buildings, JGJ/T 101-2015, China Architecture and Building Press, Beijing, China, 2015 (in Chinese).

[35] C. Xiong, X.Z. Lu, M. Hori, H. Guan, Z. Xu, Building seismic response and visualization using 3D urban polygonal modeling, Autom. ConStruct. 55 (2015) 25-34.

[36] X. Zeng, X.Z. Lu, T.Y. Yang, Z. Xu, Application of the FEMA-P58 methodology for regional earthquake loss prediction, Nat. Hazards 83 (1) (2016) 177-192.

[37] Y.J. Wu, Y. Wang, D. Qian, A google-map-based arterial traffic information system, in: Proceedings, 2007 IEEE Intelligent Transportation Systems Conference, 30 September-3 October, 2007, Seattle, USA, 2007.

[38] M. Haklay, W. Patrick, Openstreetmap: user-generated street Maps, IEEE Pervasive Comput. 7 (4) (2008) 12-18.

[39] C. Xiong, X.Z. Lu, H. Guan, Z. Xu, A nonlinear computational model for regional seismic simulation of tall buildings, Bull. Earthq. Eng. 14 (4) (2016) 1047-1069. 
473 [40] C. Xiong, X.Z. Lu, X.C. Lin, Z. Xu, L.P. Ye, Parameter determination and damage 474 assessment for THA-based regional seismic damage prediction of multi-story buildings, 475 J. Earthq. Eng. 21 (3) (2017) 461-485.

476 [41] J. Henningsson, J. Blomstrand, Tech. Rep, in: Verification and Validation of Viswalk 477 for Building Evacuation Modelling, Lund University, Sweden, 2015.

478 [42] PTV, VISSIM 9-User Manual, 2016 (Karlsruhe, Germany).

479 [43] Ministry of Housing and Urban-Rural development of the People's Republic of China 480 (MOHURD), Standard for Urban Planning on Earthquake Resistance and Hazardous 481 Prevention, GB 50413-2007, China Architecture and Building Press, Beijing, China, 4822007 (in Chinese).

483 [44] China Earthquake Administration (CEA), Emergency Shelter for Earthquake Disasters484 Site and its Facilities, GB 21734-2008, Standards Press of China, Beijing, China, 2008 (in 485 Chinese).

486 [45] Federal Emergency Management Agency (FEMA), Seismic Performance Assessment of 487 Buildings Volume 1-Methodology, Tech. Rep, FEMA-P58, Washington, D.C, 2012.

488 [46] China Ministry of Construction (CMC), Code for Seismic Design of Buildings, 489 GB50011-2010, China Architecture and Building Press, Beijing, China, 2010 (in $490 \quad$ Chinese). 